\title{
Anabases
}

ANABASES Traditions et réceptions de l'Antiquité

12 | 2010

Varia

\section{Diplomacia romana: ¿una diplomacia moderna?}

\section{Raúl Buono-Core V.}

\section{(2) OpenEdition}

\section{Journals}

\section{Edición electrónica}

URL: http://journals.openedition.org/anabases/1077

DOI: 10.4000/anabases.1077

ISSN: 2256-9421

\section{Editor}

E.R.A.S.M.E.

\section{Edición impresa}

Fecha de publicación: 1 octubre 2010

Paginación: 55-68

ISSN: 1774-4296

\section{Referencia electrónica}

Raúl Buono-Core V., « Diplomacia romana: ¿una diplomacia moderna? », Anabases [En línea], 12 | 2010, Puesto en línea el 01 octubre 2013, consultado el 20 octubre 2019. URL : http:// journals.openedition.org/anabases/1077 ; DOI : 10.4000/anabases.1077 
Anabases 12 (2010), p. 55-68.

\section{Diplomacia romana: ¿una diplomacia moderna?}

Raúl Buono-Core V.

No eXISTe ninguna ObRa DE SÍNTEsis sobre la diplomacia romana para el período real y republicano. Para Grecia destaca la obra de F. Adcok y D.J. Mosley ${ }^{1}$, y recientemente la de L. Piccirilli ${ }^{2}$. Algunos inventarios sobre embajadas se prepararon a finales del siglo XIX, pero estos no fueron muy profundos; son las listas de A. Thurm o de Th. Büttner-Wobst, este último se ocupa solo de las misiones en Roma, o la más reciente de P. Knibbe quien hace el inventario solo de las embajadas enviadas por el senado hacia el Oriente entre el año 230 y 129 a.C C $^{3}$ Existe otro catálogo de delegaciones romanas en el Mediterráneo, pero es incompleto, porque trata solo desde el año 507 hasta el 129 a.C., lo preparó E. Krug; mientras que B. Schleussner se interesa solo en los comités senatoriales de diez miembros encargados de establecer las condiciones de la paz después de las victorias de Roma ${ }^{4}$. Recientemente B.E. Thomason ${ }^{5}$ ha trabajado sobre las misiones diplomáticas entre la segunda guerra púnica y Actium, y F. Canali De

1 Diplomacy in Ancient Greece, London, 1975.

2 L'invenzione della diplomazia nella grecia antica, Roma, 2002.

3 A. Thurm, De Romanorum legatis republicae temporibus ad externas nationes missis, diss. Leipzig 1883); Тн. Воттеn-Wobst, De Legationibus, Leipzig, 1876; P. KnibBe, Die römischen Gesandtshaften nach den Osten in der Zeit von 230-129 v. Chr., Viena, 1958.

4 E. Krug, Die Senatsboten der römischen Republik, Breslau, 1916; B. Schleussner, Die Legaten der römischen Republik. Decem legati und ständige Hilfsgesandte, Munich, 1978.

5 Legatus Beiträge zur Römischen Verwaltungsgeschichte, Stockholm, 1991. 
Rossi ${ }^{6}$ lo ha hecho sobre las embajadas enviadas por el mundo griego a Roma durante el período republicano en un estudio sobre las relaciones diplomáticas de Roma entre la monarquía y la conquista de Italia (753-265 a.C), trabajos en los que se ha realizado un completo registro de cada embajada o contacto de carácter diplomático; a ellos debemos agregar el reciente libro de Claudine Aulliard ${ }^{7}$, sobre la diplomacia romana, como un instrumento de la conquista que va desde la fundación hasta el fin de las guerras contra los samnitas (753-290 a.C.). En términos generales, estos historiadores se refieren más bien, a las misiones diplomáticas romanas, o a su política exterior, pero en períodos de tiempo y espacios geográficos bastante breves. La mayoría ha preferido tratar los diversos aspectos de la diplomacia desde un punto de vista institucional, jurídico o incluso religioso, o en relación con sus implicaciones políticas. La verdad es que hacen falta enfoques más amplios, porque son herramientas útiles para una mejor comprensión de la diplomacia en un sentido global, sobre todo desde el punto de vista de su utilidad y de su evolución en el extenso período comprendido entre la fundación y el final de la República, pero me da la impresión de que no ha sido intentado hasta ahora. Otras obras de referencia como el Dicitionnaire des Antiquités grecques et romaines (Daremberg Saglio) o la Real Encyclopädie,(Pauly Wisova) no nos permiten tratar el tema mas allá del significado de las palabras relacionadas con las actividades, por ejemplo, legatio, foedus, pactum. De la misma manera, los historiadores de las instituciones no le han dedicado un capítulo a la diplomacia, como es el caso de Mommsen, quien ha dividido su análisis, en diversos capítulos centrados en el Senado o las magistraturas ${ }^{8}$.

En general los trabajos especialmente dedicados a las relaciones internacionales de Roma abordan el tema privilegiando los aspectos institucionales y jurídicos de la diplomacia a través, por ejemplo, del rol jugado por el Senado. Podemos mencionar los libros ya bastante antiguos pero no menos importantes de Coleman Phillipson y de P. Willems ${ }^{9}$, pero sobre todo los más recientes de P. Catalano y F. De Martino ${ }^{10}$. Aunque el libro de T.R.S. Brougthon tiene por finalidad establecer una lista de los magistrados en el período republicano, su trabajo nos entrega datos valiosos sobre el

6 Le ambascerie dal mondo greco a Roma in età repubblicana, Roma, 1997; id., Le relazioni diplomatiche di Roma, Roma, 2005; id., Le ambascerie romane ad gentes, in età regia e repubblicana, Roma, 2000; Le ambascerie straniere a Roma, dall'Italia e dall'Occidente, Roma, 2000.

7 La diplomatie romaine. L'autre instrument de la conquête, de la fondation à la fin des guerres samnites (755-290 av. J.-C.), Rennes, 2006.

8 Los legados del Senado, a cargo de las relaciones exteriores.

9 C. Phillipson, The international Law and Custom of Ancient Greece and Rome, 2 vols., Londres, 1911; P. Willems, Le Sénat de la République romaine, 2 vols, Lovaina, 18781885.

10 P. Catalano, Linee del sistema sovranazionale romano, 1, Turin, 1974; F. De Martino, Storia della costituzione romana, 6 vols., Napoles, 1972-1975. 
tema que nos interesa ${ }^{11}$. Hace las diferencias por ejemplo, entre los «legados embajadores», los «legados tenientes» y los «legados enviados». Sin embargo, esta clasificación, pese a la diversidad que impone las prácticas de los romanos, nos ha permitido identificar a algunas de las personas que llevaron a cabo una serie de actividades relacionadas con la diplomacia y que aparecen en este registro. Otros autores, a raíz de un enfoque diferente, han estudiado alguna función específica de la diplomacia. Es el caso de J.W. Rich ${ }^{12}$, quien ha descrito los procedimientos para la declaración de guerra; M.R. Cimma ${ }^{13}$ analiza las relaciones de amistad y las alianzas establecidas por los romanos, y G. Brizzi ${ }^{14}$, describe los modelos para reunir información. Finalmente, hay numerosos trabajos que tratan de las diferentes nociones jurídicas y religiosas, sobre las cuales se basan las prácticas diplomáticas. Por ejemplo los ya clásicos estudios sobre la noción de fides realizados por P. Boyance, A. Piganiol y sobre todo por G. Freyburger ${ }^{15}$; que son usados en el análisis de la deditio por B. Paradisi ${ }^{16}$.

Para el estudio de la diplomacia romana en tiempo de la República, disponemos de Fuentes que nos entregan datos mas bien escasos, lo que dificulta una eventual reconstrucción de cómo podrían haber sido esas primeras relaciones formales, que sin lugar a dudas, tendrán un papel relevante en la diplomacia moderna, algo que no ha sido fácilmente admitido entre los internacionalistas y cientistas políticos contemporáneos. En efecto, en los grandes manuales para el estudio de la diplomacia moderna, se considera que ella parte desde el año 1.600 de nuestra era, sobre todo, en cuanto se refiere al uso de los tratados como un instrumento que distingue a esa diplomacia. En esta oportunidad intentaré dar algunos ejemplos que nos permitan constatar que en Roma no solo existieron algunas normas e instrumentos de gran eficiencia, sino que hubo aspectos formales que se han proyectado en el tiempo hasta nuestros días, dejando su sello sobre todo en el mundo Mediterráneo. Es en esa perspectiva que me referiré a la diplomacia romana ${ }^{17}$. También, hay que tener presente que en el período en cuestión, los hechos ocurren la mayoría de las veces en occidente, con la dificultad que los datos epigráficos son pobres, a diferencia de lo que ocurre para el estudio de la diplomacia en el oriente.

Si examinamos a Polibio, más allá de los vacíos que existen entre los libros XXI y XXXIX, desde el libro XXI hacia delante, la obra es esencialmente una historia

11 T.R.S. Broughton, The Magistrates of the Roman Republic, New York, 2 vols., y un suplemento, 1952-1968.

12 Declaring War in the Roman Republic in the Period of Transmarine Expansion, Latomus, 149, Bruselas, 1976.

13 J M.R. Cimma, Reges socii et amici populi romani, Milán, 1976.

14 G. BRIZZI, I sistemi informativo dei Romani, principi e realtà nell'età delle conquiste oltremare, (218-168 a.C.), Historia, 39, Wiesbaden, 1982.

15 G. Freyburger, "Fides et potestas", en Ktéma 7 (1982), p. 177-185.

16 B. Paradisi, Deditio in fidem (Studi in onore di A. Solmi,) I, Milán, 1941, p. 285-300.

17 Para lo cual me apoyaré preferentemente en la obra de Tito Livio y de Polibio. 
diplomática, construida, como afirma Giuseppe Zecchini ${ }^{18}$, «sobre un registro, casi obsesivo de todas las embajadas, que cada año llegaban a Roma ${ }^{19}$ ", y de todas las legaciones romanas enviadas al oriente en respuesta a las solicitudes que se le hacían a Roma. Desde un punto de vista conceptual, Polibio distingue claramente entre una verdadera y legítima embajada, en la cual sus miembros gozan de un cierto margen de autonomía en la conducción de una negociación, de aquellos, que solo han sido encargados oficialmente para entregar un documento escrito. El historiador griego desde un punto de vista jurídico, no parece interesado en los aspectos relacionados con el derecho internacional, sino que más bien, se propone dejarnos una completa información sobre los embajadores, con algunos datos cronológicos sobre la presentación de las legaciones extranjeras en Roma. El texto de Tito Livio está completo hasta el 168 a.C., lo que nos permite constatar que el creciente espacio entregado a la diplomacia, no corresponde tanto a una visión subjetiva de Polibio, sino a una realidad objetiva. Su relato contiene numerosos discursos de embajadores, pero son reconstrucciones muy posteriores, generándose dudas respecto a su autenticidad. Polibio y el mismo Apiano son una contraparte, pero hay que tener presente que el valor de una fuente latina en el caso romano, es que ella utiliza la terminología propia de la diplomacia republicana.

Los romanos, no usan el término embajador, sino el de legati. De acuerdo a los datos que nos entrega el A. Ernout-A. Meillet ${ }^{20}$, el término embajador deriva del provenzal antiguo, ambaisador, (servidor), que lleva a la forma galo-latina, ambactus, término con el cual los celtas denominaban al siervo. Por otra parte, el término diplomático, es una invención que aparece en los salones del seteciento. Hasta el año 1726, no existía relación alguna entre diplomático y diplomacia. Indicaba solamente el estudio de los documentos, en general del medioevo, y el término cuerpo diplomático, se refería a la recopilación de las leyes y de los documentos de Estado (corpus). C. Phillipson ${ }^{21}$, sostiene que fue en 1791, por la acción de una cortesana de la corte de Viena, que el término pasó a entenderse dentro del mundo de los embajadores y de los ministros públicos ${ }^{22}$. Ahora bien, fue la paz de Westfalia, firmada el 24 de octubre de 1648 , y ratificada en 1649, junto a los tratados posteriores, la que promueve las relaciones comerciales y sobre todo diplomáticas entre los estados europeos. Es en los congresos de Viena y de Aquisgrán en 1815 y 1818 respectivamente, que se establece la jerarquía de los agentes diplomáticos, embajadores, ministros plenipotenciarios, enviados extraordinarios y encargados de negocios ${ }^{23}$, tal como se entienden hoy día. Pero todo aquello será el resultado de un proceso en que tanto en el mundo griego como en

18 Ambasciate e ambasciatori in Polibio (Diplomacia y autorepresentación en la Roma antigua), Vitoria-Gasteiz, 2005, p. 11-23.

19 ZeCCHINI, Ambasciate, p. 11.

20 Dictionnaire étymologique de la langue latine. Histoire des mots, París, 1959, s.v. ambactus.

21 The Internacional law and custom of Ancient Greece and Rome, London, 1911.

22 S. Nava, s.v. Diplomazia e diplomatici, p. 654.

23 C. Phillipson, The International Law, p. 304. 
el romano, se tejerá, poco a poco, la antesala de gran parte del tramado de lo que será, desde un punto de vista formal, la diplomacia moderna.

La situación del mundo Mediterráneo después de la guerra Siria y la paz de Apamea, nos permite ver que Roma ya es considerada una potencia hegemónica de carácter mediterráneo, arbitrando los conflictos y tensiones regionales, con una superioridad militar que le permite intervenir con la herramienta de la presión diplomática, sin necesidad de recurrir al uso de las armas, tal cual como se hace en algunas ocasiones hoy. Por otra parte, los embajadores en la antigüedad, a diferencia de los actuales que gozan de amplios poderes, no tenían una autonomía total, limitándose más bien, a persuadir a sus interlocutores de las ventajas de la propuesta de la cual eran sus portadores; en los hechos, el arma más importante de la diplomacia griega, estaba en el arte de convencer al auditorio ${ }^{24}$. Por eso los enviados fueron casi siempre expertos oradores, capaces de hacer entender sus razones a los ciudadanos, y a los que en las poleis, se dedicaban a la diplomacia.

Según Polibio ${ }^{25}$, en Roma las embajadas eran recibidas por el Senado al comienzo del mes de Enero, antes que los cónsules se hicieran cargo de su imperium. Sabemos que los embajadores de pueblos considerados aliados, eran alojados intra pomerium, y recibidos inmediatamente, en cambio los pueblos considerados poco amistosos, eran sometidos a una larga espera extra pomerium. El rechazo a recibir un embajador, indicaba la molestia de los senadores, pero no debía interpretarse necesariamente como un casus belli. Polibio nos entrega el dato para el invierno del 167-166 a.C., con Eumenes II de Pergamo, un aliado tradicional de Roma, pero sospechoso de relacionarse y tenerle simpatía a Perseo ${ }^{26}$. Polibio y Tito Livio, hacen presente de la vigencia de un senatus consulto que prohíbe a cualquier rey ingresar a Roma, evitándose en este caso implicar directamente a Eumenes, quien no es admitido dentro del pomerium, lo que demuestra el comienzo de un estilo y un cierto refinamiento que se perfilará progresivamente en la diplomacia hasta nuestros días. A los embajadores se les garantizaba su inviolabilidad no solo en Roma y en el territorio controlado por los romanos. Cuando en el 189 a.C. los enviados por los Etolios fueron secuestrados por los epirotas, durante el viaje de regreso de la Urbs a su tierra, el Senado romano envió una carta en la cual exigía la liberación inmediata de dichos diplomáticos sin pago de ningún rescate, petición a la cual, los responsables del secuestro, finalmente accedieron. Polibio nos entrega datos sobre la prolífera actividad diplomática que lleva a cabo la confederación Etólica. Las

$2535,2-3$.

$2630,18-19$. 
embajadas son introducidas en la curia, en el Senado, por un cónsul ${ }^{27}$. El mismo Julio César recuerda que introdujo a diversos embajadores ${ }^{28}$.

Los legati o los embajadores romanos, son representantes de la comunidad, y son elegidos con el fin de proyectar la imagen de Roma en otras comunidades y pueblos. Deben también transmitir el mensaje que se les encarga. Por las evidencias que se recogen en las fuentes y sin necesidad de hacer un gran esfuerzo imaginativo, debemos suponer que Roma después de las Guerras Púnicas, recibió una gran cantidad de embajadores, lo que la convirtió poco a poco, en un escenario político único en el mundo mediterráneo ${ }^{29}$. Este carácter excepcional, nos permite ver, como en las bambalinas de un gran teatro, a las diversas embajadas que esperaban ser recibidos en el vestíbulo del Senado, o en otros espacios públicos. Se da una situación que comienza a ser habitual: el pueblo romano tiene la posibilidad de observar directamente a los conquistados o sometidos al poder de Roma. Tito Livio enfatiza en la teatralidad de los embajadores, quienes cuando pronunciaban el discurso, logran producir un gran efecto en el auditorio en el momento de su presentación ${ }^{30}$. Dramatismo y retórica que dejaba al auditorio conmovido.

Una oportunidad para comprobar también lo relevante de la gestualidad, es el conocido paso en Tito Livio, en el que relata cuando el 218 a.C. son enviados a África, cinco embajadores romanos con la misión de preguntar a los cartagineses si Aníbal había atacado Sagunto por decisión propia. Una vez que presentan sus motivos al senado cartaginés, un miembro de este les pide que revelen sus verdaderas intenciones. Entonces uno de los embajadores romanos, plegando su toga (sinu ex toga facto), dice que en ella trae la paz o la guerra, que elijan, a lo que el cartaginés responde con la guerra. El romano, envolviéndose nuevamente en la toga (iterum sinu efuso), acepta la declaración de guerra, iniciándose oficialmente la Segunda Guerra Púnica ${ }^{31}$. Estos

27 Tito Livio, 30, 21, in senatum introductis.

28 F. CANALI DI Rossi, Il ruolo dei patroni nelle relazioni politiche fra il mondo greco e Roma in età republicana ed augustea, München-Leipzig, 2001.

29 J. LINDERSKI, "Ambassador go to Rome", en Les relations internationales, E. Frézouls, A. Jacquemin eds., Paris 1995, p. 453. También M. Bonnefond-Coudry, "Contrôle et traitement des ambassadeurs sous la République romaine”, en C. MOATTi (a cura di), La mobilité négociée, Paris (in c.d.s.); D.J. Bedermann, "Making Friends: Diplomats and Foreign Visitors in Ancient Times" en International Law in Antiquity, Cambridge, 2000, p. 88-136 y últimamente Claude Eilers (ed.), Diplomats and Diplomacy in the Roman World, en Mnemosyne Supplements 304, Leiden-Boston, 2009; sobre esta publicación conviene revisar la reseña de F. Canalı di Rossi in Bryn Mawr Classical Review, 2009.08.68, quien lo considera un estudio parcial porque los autores ignoran los primeros cinco siglos de relaciones diplomáticas en Roma.

$3043,7,5$.

31 Tito Livio, 21, 18, 12-14. También en Polibio, 3, 33,2; Diodoro de Sicilia, 25,16; Silio Italico, Pun., 2, 384-389; Floro, 1, 22; Apiano, Bell. Hisp., 13.Si bien es cierto que a pesar que los discursos de embajadores contenidos en la obra de Tito Livio son discursos recons- 
hechos dejan en evidencia que la oratoria y la gestualidad frente a sus interlocutores son parte del arte de la representación de los diplomáticos.

El término legati, es el más usado para designar a los embajadores, Tito Livio en muy pocas ocasiones se refiere a los embajadores como a los oratores, haciéndolo solo en un contexto muy especial. Polibio nos recuerda que la diplomacia es un asunto de los cónsules y del Senado, organismo, que como sabemos, tuvo la responsabilidad de las relaciones exteriores de Roma. Cómo en esos tiempos dicho organismo es eminentemente aristocrático, y elige a los legati, parece lógico pensar que la mayoría de esos embajadores pertenecían a ese círculo ${ }^{32}$, dato, que los estudios prosopográficos, en gran medida, han sido capaces de demostrar. Los embajadores entonces, no solo cumplían una misión específica, sino que proyectaban además la imagen del patriciado y del pueblo romano. Pero se requería también de otras cualidades que pesaban en los criterios de selección de los embajadores. Tal como en la mayoría de los casos de hace hoy, además de las cualidades que ya hemos señalado, debían ser personas a quienes se les reconociera a la hora de hacer una evaluación, su capacidad de comunicación, o su capacidad oratoria y de negociación. G. Clemente en su ya clásico trabajo sobre las embajadas romanas, considera que la misión persuasiva en favor de Roma es definitiva $^{33}$. Debo recordar que estos requisitos no son un invento de la diplomacia romana, ya que también formaban parte de las características de las embajadas griegas en el período clásico. Los discursos en Grecia tenían el fin de persuadir más de que negociar, porque el objetivo era atraerse el apoyo de las asambleas en las cuales comparecían. Era importante que la persona enviada tuviera un reconocido prestigio entre los opositores, de modo que demostrara la capacidad de influir favorablemente en la asamblea a la cual debía dirigirse ${ }^{34}$. A la figura de los embajadores, había que agregar, el que tuvieran una cierta edad; esto más que nada, por la importancia de los asuntos que debían tratar, por lo cual, la experiencia política que daban los años de desempeño en cargos públicos, era un excelente antecedente. La diplomacia griega valoraba también el buen aspecto físico, ya que demostraba una congruencia entre la armonía externa y la bondad del discurso del enviado ${ }^{35}$, lo que encarnaba los antiguos ideales de la belleza física y la

truidos con posterioridad a los hechos, ellos son portadores del espíritu que animaba a esos actores comprometidos.

32 Me refiero especialmente a la fundamental obra de M.T.R. BRoughton, The magistrates of the Roman Republic, 2 vols. New York, 1950-1960.

33 G. Clemente, "Esperti ambasciatori del senato e la formazione della politica estera romana tra el I e il II secolo a.C”, en Athenaeum, 53 (1976), p. 320-322, demuestra que la diplomacia es asunto del patriciado y de las instituciones que representan, en otras palabras, del Senado y del Consulado.

34 Piccirilli, L'invenzione, p. 71-72.

35 Tito Livio, 21, 14. E. Torregaray, "Embajadas y embajadores entre Hispania y Roma en la obra de Tito Livio", en Diplomacia y autorepresentación en la Roma antigua, VitoriaGasteiz, 2005, p. 33; PICCIRILli, L'invenzione, p. 23-28. 
belleza espiritual. Entonces tiene sentido que el pertenecer al patriciado, la habilidad oratoria, la experiencia política, el prestigio público, y la madurez, eran, con muchas probabilidades, el perfil ideal de las representaciones diplomáticas romanas en época republicana.

A todos estos antecedentes, debemos agregar que la diplomacia romana va evolucionando en la medida que Roma se va haciendo más fuerte. Como ya hemos señalado, en los primeros tiempos, los embajadores eran los transmisores eficientes de un mensaje, pero desde los inicios de la Segunda Guerra Púnica, y a medida que la conquista romana avanzaba, el mensaje de las legaciones fue paso a paso transformándose, llegando a convertirse en un instrumento que tenía más bien la misión de dar a conocer las órdenes de Roma. Las conquistas transforman a la ciudad en un eje, al que los pueblos en proceso de conquista convergen, convirtiendo a la ciudad en un escenario, en una especie de vitrina, en el cual los extranjeros también se exhiben. Tito Livio afirma que los embajadores van porque parte fundamental de su misión es ser escuchados (...quod admissi auditique sunt...), deben ser oídos (audire) ${ }^{36}$. Pero al mismo tiempo las legaciones van a dejarse ver cuando son introducidas en el Senado (...legaciones... in senatum introductae auditaeque...) ${ }^{37}$, lo que por cierto exigirá de una puesta en escena propia de la diplomacia, que permitirá a los romanos observar a los embajadores y a su cortejo, momento en el cual, al igual que en la ceremonia del triunfo, los ayudará a formarse una idea aproximada sobre el carácter y el aspecto de esos extranjeros y de esa manera, formarse una opinión directa ${ }^{38}$. Seguramente la sensación de estar en un escenario como el que se describe, influyó también en el ánimo de los embajadores extranjeros, algo que probablemente los romanos buscaron premeditadamente. Se imponía a las embajadas la necesidad de producir un efecto positivo en el auditorio romano, que en algunas ocasiones, podía incluso conmover a los senadores $^{39}$. En esos momentos, se daba una estrecha relación entre la comunicación oral y el impacto visual. En cierto modo, como resultado del arte de la retórica clásica llevada a su máxima emotividad ante la teatralidad de la puesta en escena, había una contaminación de la práctica política, más fría y calculadora. La diplomacia, que formaba parte de esa acción política y que compartía con ella el uso de la retórica, ponía también en juego esa teatralidad, a la que se debía agregar, el acto de recepción, que se convertía en un hecho teatral similar a otras grandes manifestaciones públicas romanas, como los desfiles funerarios o el triunfo entre otras. Elena Torregaray en un valioso estudio sobre las embajadas entre Hispania y Roma, considera que no hay que olvidar que gran parte del efecto que nos producen estas embajadas son responsabilidad del relato que hace

\footnotetext{
$36 \quad 21,10$.

37 Tito Livio, 28, 39, 1.

38 Torregaray, Embajadas, p. 44.

39 T. Sсніск, "Cicero and the pathetical appeal in oratory", en Classical Bulletin, 42, 2 (1965), p. 1-4.
} 
Tito Livio; porque encuentra que algunos de los elementos retóricos que apreciamos en sus descripciones de acciones diplomáticas, pertenecen más al estilo del historiador que a la realidad histórica del momento ${ }^{40}$. Hay que separar entonces, entre una retórica diplomática y una retórica historiográfica. Esta teatralidad empapa la acción de los embajadores, formando parte de él, e influyendo en el escenario que generalmente es la ciudad de Roma, pero que luego se concentra en el espacio del Senado donde son recibidos los actores que la ponen en escena, es decir, los miembros de las embajadas y el público que presencia el espectáculo, que está compuesto principalmente por los senadores y el pueblo de Roma.

Si hiciéramos una rápida comparación con la diplomacia moderna, se puede ver que la mayoría de esas características se mantienen hasta hace poco tiempo atrás. El acto de presentación de las cartas credenciales de los embajadores ante un gobierno determinado, está revestido de una gran solemnidad y porque no, de una cierta teatralidad. No nos olvidemos que hasta hace muy poco tiempo, los embajadores usaban sus solemnes y elegantes uniformes diplomáticos, que se transformaba, principalmente por un asunto de imagen pública y política, en una verdadera competencia de entorchados, condecoraciones y bicornios. Sabemos que durante el transcurso de la guerra anibálica, cuando los romanos se enfrentan a los galos y a los hispanos, los iberos parecen haber usado una túnica de lino entretejida con púrpura ${ }^{41}$ La única gran diferencia, es que hoy día, los embajadores son preferentemente acreditados de modo permanente ante un estado, en cambio en el mundo antiguo, tenían el carácter de enviados a una misión especial, por el tiempo que fuese necesario, el que generalmente era breve. En base al derecho internacional actual, la condición jurídica en la que se amparan los embajadores está representada por la extraterritorialidad, o inmunidad ante la coacción del estado en el cual residen, la que se extiende a los miembros de su familia con los cuales convive, y al personal de la misión, y que se traduce, en lo que se conoce como la inmunidad diplomática. Desde un punto de vista personal, la extraterritorialidad tiene que ver con la inviolabilidad de la persona y la exención del embajador de la jurisdicción civil y penal del estado del que es huésped. Esto también incluye la inmunidad del domicilio de la representación diplomática. En cambio, como vemos, tanto en Grecia como en Roma, los embajadores no gozaban de estos beneficios, no cubrían una magistratura, sino que eran los portadores de un mandato o los encargados de una misión en una ciudad o estado en la cual permanecía solo el tiempo que fuese necesario. Tampoco gozaban de la inviolabilidad de la persona del embajador.

Los embajadores en Grecia eran elegidos por las asambleas populares, en cambio en Roma, lo hacía el Senado. Del mismo modo los embajadores romanos esperaban ser

40 Torregaray, Embajadas, p. 45.

41 Tito Livio, 22, 47, 5-6; Torregaray, Embajadas, p. 51; M.P. Garcia-Gelabert, J.M. BlazQUeZ, "Mercenarios hispanos en las fuentes literarias y en la arqueología", en Habis, 18-19 (1987-1988), p. 257-259. 
recibidos por una asamblea representativa, en un espacio constitucional, porque esto les proporcionaba validez. Tito Livio relata que cuando el hispano Alorco se dispone a entrar a Sagunto para negociar la paz, lo rodean omnis generis hominum ${ }^{42}$, pero Alorco, es llevado frente al Senado de la ciudad. El carácter oficial de los enviados exige que se Presente ante una asamblea, una autoridad o una institución. La otra cara de la moneda, la vemos cuando en otro momento, Aníbal se niega a recibir a los embajadores romanos enviados a Hispania por el Senado, y ordena que sean recibidos ad marem ${ }^{43}$, en la costa, en un lugar inapropiado que no corresponde, lo que es una clara manera de enfrentar a los legati y generar una controversia.

Así vemos entonces que en Roma, ya se pueden distinguir las primeras normas que dan forma al funcionamiento de una diplomacia. Se hace habitual que el Senado las reciba a comienzos del año, costumbre que se oficializó con la lex Gabinia, que establece el mes de febrero para esos trámites ${ }^{44}$. El mismo Cicerón sostiene que según la ley, el Senado, como un escenario de la práctica diplomática, como un espacio sin armas para darle realce a la importancia de la palabra, debía recibir a las embajadas todos los días laborales, desde el $1^{\circ}$ de febrero hasta el $1^{\circ}$ de Marzo ${ }^{45}$. Para esto existía un protocolo de admisión, según el cual, los legados eran anunciados (nuntiatum est) ${ }^{46}$. El Senado decidía si los recibía o no, ya que como he señalado, los enemigos estaban excluidos del pomerium, por lo que a veces se les escoltaba. Esto habla de un cuidadoso control sobre las embajadas y de su tránsito por la ciudad. Las embajadas esperaban su turno para ser recibidos; hay relatos que demuestran que los saguntinos lo hicieron en el vestibulum de la Curia, donde además se exponían públicamente los regalos que traían al pueblo de Roma ${ }^{47}$. En este caso llevan como ofrenda una corona de oro que desean depositar en el Capitolio, en el templo a Júpiter Optimo Maximo. Mientras los embajadores esperaban, eran seguramente observados por el público romano presente en el comitium y en el foro, generándose un gran efecto en el auditorio. Este procedimiento nos sugiere una componente de exposición pública, en la cual los saguntinos exponen su riqueza a la vista de los senadores. El intercambio de regalos diplomáticos ha existido siempre, y en Roma, un embajador amigo, no llega ni se va jamás con las manos vacías ${ }^{48}$. Se dan entonces, dos jerarquías en el público, uno popular y otro aristocrático. Tito Livio relata que el público romano escucha a las embajadas en silencio, lo que demuestra también, el grado de madurez que había alcanzado el pueblo romano, y por otra parte, el respeto que los embajadores imponían en el momento de su alocu-

$42 \quad 21,12$.

43 Tito Livio, 21, 9-10.

44 M. Coudry, "La lex Gabinia sur les ambassades", en C. Nicolet, Des ordres à Rome, Paris, 1984, p. 62.

45 Ciceron, Q.F. 2, 11, 3.

46 Tito Livio, 21, 9.

47 Tito Livio, 30, 21.

48 Torregaray, Embajadas, p. 56. 
ción. Al parecer, los romanos interrumpían a los embajadores cuando estos no eran la mejor elección, lo que consideraban una falta de deferencia de la otra parte, al no enviar a su gente más capacitada. Sabemos de casos, en que los embajadores, fueron expulsados a gritos por los senadores, negándose a escuchar su discurso ${ }^{49}$. Para los romanos el silencio en la recepción de las embajadas es una señal de respeto y de reconocimiento hacia la autoridad y la representatividad política del orador. Esta es una característica netamente romana, en cambio, la falta de respeto, es lo común en otras latitudes: el mismo Tito Livio nos relata el momento en que los embajadores romanos son recibidos por los galos, los que en su asamblea interrumpen el discurso de estos con gritos y manifestaciones ruidosas, impidiéndoles que transmitieran el mensaje que se les había encomendado. La diplomacia es sobre todo, una cuestión de palabra ${ }^{50}$

El efecto visual causado por esas embajadas dependía de la composición de la comitiva, o mejor, dicho, del equipo. En muchas ocasiones los embajadores iban acompañados de un séquito, que aumentaba el volumen de la legación, No sabemos cuales eran las funciones del equipo, siendo muy probable que varios de sus miembros ayudaran en las tareas diplomáticas. Se podía llegar a formar una comitiva impresionante, incluso, llegando a ocupar varias naves para su traslado ${ }^{51}$.

Sobre esto, el mismo historiador nos relata un hecho que ejemplifica aún más el efecto visual sobre el público. Me refiero al relato de la conmovedora entrada en el Senado de la delegación de los calcidenses, con Micitión, su líder, en una litera, porque tenía paralizadas las piernas, con un discurso en el que señala, que va a utilizar la única parte de su cuerpo que le queda viva, esto es, la lengua, para deplorar las calamidades en su patria ${ }^{52}$. Este dramático caso nos permite ver los diversos recursos a los que las embajadas extranjeras recurrían a fin de obtener las metas que se habían propuesto. El tiempo de que disponían para la presentación en el Senado, era limitado, porque dicho organismo, debía recibir a otras embajadas en la misma jornada. Había por lo tanto, que intentar establecer alguna diferencia favorable que las distinguiera entre las demás, que hicieran de la visita algo memorable y digna de ser recordada. Dentro del acto de la recepción, los legati podían entrar y salir de la Curia varias veces, según como fueran las discusiones de los senadores en torno a su visita ${ }^{53}$. Si toda esta actividad se alargaba, los embajadores tenían que quedarse en Roma, donde podían incluso llegar a constituir un pequeño grupo de presión, situación que podía llegar a incomodar a los senadores, por lo que dicho organismo se preocupaba en la medida de lo posible, de darle soluciones rápidas a los diversos asuntos que se les planteaban ${ }^{54}$. Hay casos en

49 Es el caso de los jóvenes cartagineses enviados a Roma como embajadores.

50 Tito Livio, 21, 19.

51 R. Chevalier, Voyages et déplacements dans l'empire romain, Paris, 1988, p. 212-213.

52 Tito Livio, $43,7,5$.

53 Tito Livio, 43, 2.

54 El caso de los embajadores hispanos enviados a Roma el 171 a.C. y de quienes Tito Livio informa que su presencia en Roma y sus continuas peticiones llegaron a resultar tan incó- 
que una embajada solicita a los romanos visitar el país, para conocerlos mejor; en ese caso se sabe que se les coloca a disposición guías y cartas de presentación en los lugares donde vayan, guías que seguramente eran traductores, por los problemas de comunicación que deberían enfrentar. Cicerón afirma por ejemplo que los cartagineses usaban un intérprete cuando se enfrentaban al Senado romano ${ }^{55}$. No sabemos hasta ahora, si estas embajadas se presentaron ante las asambleas y magistrados locales. Se produce entonces, una forma de flujo cultural en ambas direcciones, que permite la transmisión de las impresiones permitiendo, sobre todo a los pueblos sometidos, formarse una mejor idea de quienes eran sus conquistadores, una buena manera de transformar a los vencidos en convencidos. Lo mismo se puede constatar en la famosa inscripción del decreto de Abdera, en la cual se muestra la curiosidad de los griegos por las prácticas y las instituciones romanas, lo mismo que por su lengua ${ }^{56}$.

Tal como en nuestro tiempo, es posible que en esa época también se haya producido otro tipo de práctica diplomática, la no institucional ${ }^{57}$. Se trataría de la diplomacia reservada, que es más bien secreta, al margen de lo público, y que estaría marcada por una confidencialidad no exenta de suspicacias ${ }^{58}$. Tito Livio esto lo ve como algo negativo; estimado como un comportamiento alevoso el actuar en la oscuridad, la noctu, es algo cercano a lo perverso, cercano a lo que no se debe hacer. Este modo de llevar las relaciones diplomáticas al margen de la representación oficial, se proyecta a través de los siglos, y se relaciona más bien, con los mensajes secretos, situación que la mayoría de las veces alimentaba la relación entre diplomacia y engaño, con una real importancia ${ }^{59}$. Piccirilli ${ }^{60}$, piensa que la diplomacia griega se configuró también, como la mejor cobertura para una actividad clandestina, que tuvo la finalidad de recoger

modas que los senadores alcanzaron una solución rápida que les permitiera olvidarse de ellos. Tito Livio; 43, 2, 1 ; F. Canali Di Rossi, Il ruolo dei patroni, p. 9-10.

55 De. Div, II, 64, 131.

56 A. Erskine, "Greek embassies and the City of Rome", en Classical Ireland, 1 (1994), p. $1-2$.

57 M. Lecomte, "Les méthodes de la diplomatie romaine chez les historiens latins", en Caesarodonum, 4 (1969), p. 229-230; Raul Buono-Core V., "Relaciones, Información, Espionaje y Servicios de inteligencia en Roma", en Semanas de Estudios Romanos, XI, (2002), p. 65-83. Ver también GIOvanni BrizzI, I sistema informativi dei Romani, Principi e realtà nell'età delle conquiste oltremare (216-168), en Historia, Heft. 39, Wiesbaden 1982; W.G. Sinnigen, "The Roman Secret Service”; en Classical Journal, 57, (1961), p. 65-72. Para el caso de los delatores tanto en Grecia como en Roma ver H. Russel, "Advancement in Rank Ander the Roman Republic as a Reward for the soldier and the Public Prosecutor", en BMD, (1955); G. BoIsSIERE, L'accusation publique et les délateurs chez les Romains, Niost 1911; J.O. LofBerG, Sycophancy in Athens, Chicago, 1917; id., "The Sycophant parasite", en CPh, 15, (1920), p. 71-72.

58 Tito Livio, 26, 30, 1-12.

59 F. Gazzano, "La diplomazia nelle Storie di Erodoto. Figuri, temi, problemi", en La retorica della diplomazia nella Grecia antica e a Bizancio, Roma, 2002, p. 10-11, 65-67.

60 PicCIRILLI, L'invenzione, p. 116. 
informaciones políticas y militares, algo que es probable que en el caso romano también ocurriera. Por lo tanto, era aparentemente una diplomacia informal, pero como esas actividades se entendían como parte de ese juego, pasaron a ser formales, porque en los hechos se aceptaban y estaban respaldadas por los Estados.

Vemos entonces embajadores romanos que muestran un comportamiento que según Tito Livio, es un ejemplo de dignitas, una proyección de la grandeza de Roma y de sus instituciones; y por otra parte, embajadores extranjeros, que aparecen casi siempre como suplicantes y solicitantes ${ }^{61}$. En Tito Livio, vemos que la imagen normal de una embajada llegando a Roma, es la de un grupo de suplicantes ante el Senado, solicitando paz, perdón, justicia o expresando su gratitud, en una postura de postulantes y gratulantes. Incluso, cuando se trataba de pedir la paz, los embajadores podían tomar la posición física de un suplicante, $y$, cuando deseaban quejarse por un maltrato, podían llegar a hincar la rodilla ante los senadores romanos, suplicando, convirtiéndose así en suplicantes, que es lo que hacen los hispanos de la embajada del 171 a.C. ${ }^{62}$ Esta es una situación que está regulada por el mayor o menor poder que Roma logra en un determinado período de su historia. Es evidente por lo tanto, que en los primeros tiempos, veamos también a los romanos en una actitud más bien peticionaria, solicitando ayuda frumentaria, religiosa y jurídica.

Debemos también considerar que es muy posible que haya existido bastante diferencia entre el modo y el método para entablar y mantener relaciones con el oriente que con el occidente del Mediterráneo. C.W. Wooten, afirma, en un importante articulo sobre las embajadas romanas en el mundo helenístico, que «habría que añadir un elemento con peso político en la oratoria de los embajadores, y es que la diplomacia romana mantenía en Oriente con los interlocutores del mundo helenístico, un tipo de discurso bastante diferente al que desarrolló en occidente con las poblaciones itálicas, celticas e hispanas ${ }^{63}$ ». En ambos casos, los primeros contactos fueron claves, porque determinaron las posteriores relaciones de Roma. Entre las dos guerras púnicas se establecieron contactos con ciudades y ligas griegas e hispanas, con las que antes no se había podido hacer nada. Es el caso de Marsella, en el occidente, lo cual influyó en otras relaciones de esa área. Tito Livio dice que en los discursos de los legati romanos, se veía un tono común, que consistía en una apariencia un tanto suave, pero con un fondo contundente ${ }^{64}$, en otras palabras, los romanos se mostraban implacables bajo una apariencia serena ${ }^{65}$.

61 Chevalier, Voyages, p. 212.

62 Tito Livio, 43, 2, 1-12.

63 C.W. Wooten, “The Ambassador's Speech; a particular Hellenistic genre of oratory", en Quaterly Journal of Speech, 59 (1973), p. 209-212.

64 Quo lemus agunt segnius incipiunt, eо cum coeperint uereor ne perseuerantius saeuiant, 21, $10,7$.

65 Tito Livio, 21, 18, 4-5. 
Finalmente, estos hechos y situaciones, que se van entretejiendo, nos permiten, sin hacer un gran esfuerzo, con los innumerables ejemplos que la antigüedad grecorromana nos entrega, ver gran parte de los fundamentos, de lo que al menos podríamos denominar, los inicios de un estilo diplomático formal, que se proyectará inexorablemente hasta nuestros tiempos. Si aceptamos que hoy la diplomacia es la herramienta que se encarga de las relaciones entre los estados soberanos, los romanos la tuvieron desde su fundación, convirtiendo el foedus, en un instrumento clave para incorporar a los vencidos al mundo romano, concediéndoles la ciudadanía, incorporándolos plenamente a su realidad política y jurídica ${ }^{66}$ en términos de igualdad y anticipando una metodología moderna para las relaciones. El foedus busca desde los primeros tiempos la unión los dos grupos, concediéndole una serie de beneficios aceptando y acogiendo al grupo vencido, transformándoles en convencidos. Se establece así, lo que podría llamarse una confederación, en la que desaparecen vencedores y vencidos, para hermanarse, formar una nueva unidad engrandecida, un método usual desde los orígenes, para la expansión romana ${ }^{67}$.

Raúl BuONO-CORE V.

Instituto de Historia

Pontificia Universidad Católica de Valparaiso

Casilla 4059-Valparaiso-Chili

mailto:rbuonocu@ucv.cl

66 Ver A. Guillet, Envoys and political communication in the late antique West 411-533, Cambridge, 2003.

67 Raul Buono-Core V., Roma Republicana: Estrategias, Expansión y Dominios (525-31 a.C.), Valparaíso, 2002-2003, p. 2. 